\title{
ALOCAÇÃO DE RECURSOS (CARBOIDRATOS) NO DESENVOLVIMENTO INICIAL DE PLÂNTULAS DE Schizolobium parahyba (Vell.) S.F. Blake (FABACEAE - CAESALPINIOIDEAE) ${ }^{1}$
}

\author{
Emanuela Wehmuth Alves Weidlich ${ }^{2}$, Rosete Pescador ${ }^{3}$ e Alexandre Uhlmann ${ }^{4}$
}

\begin{abstract}
RESUMO - Utilizou-se Schizolobium parahyba, objetivando analisar a alocação dos teores de açúcares solúveis totais e de reserva (amido) e biomassas no desenvolvimento das plântulas. Após a quebra de dormência, 200 sementes foram semeadas em substrato composto por casca de arroz carbonizada e areia. Em cada coleta foram utilizadas 10 amostras para dosagem de açúcares solúveis totais e amido e 10 para mensuração das massas frescas e secas (MS e MF) no $7^{\circ}, 14^{\circ}, 21^{\circ}, 28^{\circ}, 35^{\circ}$ e $42^{\circ}$ dia após a germinação (DAG). As sementes apresentaram 94,5\% de germinação. Os açúcares solúveis totais estão em maiores quantidades nas raízes, hipocótilo e epicótilos. Os cotilédones apresentaram maiores teores de amido, já que este é um órgão de reserva. O aumento da MF é diretamente proporcional ao incremento de açúcares solúveis e amido nas estruturas analisadas. As relações de biomassa e teores de açúcares solúveis totais e amido encontrados ressaltaram a mobilização dos compostos de reserva dos cotilédones nas outras partes da planta, à medida que a redução da biomassa e de açúcares dos cotilédones reflete o aumento na produção de biomassa de epicótilos, hipocótilos e raízes da plântula.
\end{abstract}

Palavras-chave: Alocação de recursos, Carboidratos e Amido.

\section{RESOURCE ALLOCATION (CARBOHYDRATES) IN THE INICIAL DEVELOPMENT OF SEEDLINGS OF Schizolobium parahyba (Vell.) S.F. Blacke (FABACEAE - CAESALPINIOIDEAE)}

\begin{abstract}
The allocation of resources in Schizolobium parahyba was analyzed measuring the total soluble sugars, starch levels and biomass. After breaking dormancy, 200 seeds were sown in substrate composed of rice rind and sand (1:1). Ten seedlings were collected to measure the soluble sugar and starch level and ten were used to measure the fresh biomass (MF) and dry biomass (MS) on the 7, 14, 21, 28, 35 and 42 days after germination (DAG). The seeds showed a 94.5\% germination rate. The total soluble sugar levels were greater in roots, stems and epicotyls. The cotyledons had the greatest starch level because they are the store organs of this plant. The increase of MF is directly proportional to the increment of total soluble sugars and. The relation between biomass, total soluble sugar and starch have shown the mobilization of the store from cotyledons to the other structures of the plant while the reduction of biomass and sugars of cotyledons result in an increase of biomass in epicotyls, stems and roots of the seedling.
\end{abstract}

Keywords: Allocation of resources, Carbohydrates and Starch.

\footnotetext{
${ }^{1}$ Recebido em 14.04.2008 e aceito para publicação em 02.03.2010.

${ }^{2}$ Programa de Pós Graduação em Engenharia Florestal na Universidade Federal do Paraná, UFPR, Brasil. E-mail: <emanuelawa@yahoo.com.br>.

${ }^{3}$ Universidade Federal de Santa Catarina, UFSC, Brasil.

${ }^{4}$ Embrapa Florestas, EMBRAPA, Brasil.
} 


\section{INTRODUÇÃO}

O destino das populações vegetais está relacionado com os eventos que ocorrem com seus indivíduos no início de suas vidas (GRUBB, 1977).

Para que os organismos utilizem os recursos disponíveis na natureza de forma otimizada, são necessárias mudanças adaptativas na sua forma e função. Para isso alocam recursos de forma variada, efetuando trocas, pois, enquanto os recursos estão sendo alocados para uma estrutura, eles não estão disponíveis para outra. Esses mecanismos variam para cada espécie e dependem das condições disponíveis no ambiente. Os organismos têm como objetivo principal produzir gerações bem-sucedidas, portanto os estágios iniciais de uma planta são extremamente importantes para o seu sucesso reprodutivo (RICKLEFS, 2003).

As reservas das sementes, sendo as principais os carboidratos, lipídeos e proteínas, estão relacionadas com a manutenção e desenvolvimento do embrião até a formação da plântula. Podem funcionar como fonte de energia para manter os processos metabólicos e como fonte de matéria para a estruturação de tecidos vegetais que garantirão a formação de uma plântula (KERBAUY, 2004; BUCKERIDGE et al., 2004a).

As plantas são aptas a produzir açúcares oriundos da fotossíntese, tendo também alto potencial de modificar seu desenvolvimento em resposta à disponibilidade desses açúcares (TREVISAN et al., 2003; GIBSON, 2003). Portanto, a maior parte do carbono fixado na fotossíntese é utilizado para formação de carboidratos, principalmente sacarose e amido, que fornecem energia para a respiração e esqueletos de carbono para sintetizar outras moléculas (KERBAUY, 2004).

Em trabalho com Euphorbia heterophylla, Suda e Giorgini (2000) encontraram inicialmente grande biomassa e teores de açúcares solúveis no endosperma (tecido de reserva), seguido da redução de ambos, enquanto ocorreu aumento de biomassa e açúcares solúveis nos embriões. Anteriormente, Buckeridge e Dietrich (1996) descreveram em Sesbania marginata diminuição das biomassas nos endospermas ao longo do desenvolvimento da semente e início da germinação, mostrando que os órgãos de reserva acumulam carbono para posteriormente distribuir para as demais partes da plântula.
No processo de germinação e desenvolvimento de plântulas, a distribuição de recursos é complexa. Assim, o objetivo deste trabalho foi analisar fisiologicamente a alocação de recursos ao longo do desenvolvimento inicial de plântulas de S. parahyba, correlacionando as suas biomassas nas diferentes fases de desenvolvimento com a quantidade de carboidratos solúveis totais e de reserva em cada uma de suas partes (cotilédones, hipocótilos, epicótilos e raízes). Dessa forma, procurou-se obter dados fisiológicos que auxiliem a compreensão do desenvolvimento dessa espécie pioneira.

\section{MATERIAL E MÉTODOS}

\subsection{Descrição da espécie e montagem do experimento}

S. parahyba é característica da Floresta Ombrófila Densa, principalmente na planície aluvial e início de encostas. É espécie pioneira e ocorre em abundância em florestas secundárias, especialmente em clareiras. Sua ocorrência natural é do sul da Bahia ao Rio Grande do Sul e em países da América Central. S. Parahyba é uma árvore semicaducifólia, com 10 a 25 m de altura e 30 a 60 cm de DAP (diâmetros à altura do peito). Tem copa ampla, ramificação cimosa, folhas alternas, compostas e bipinadas. Possui flores grandes e vistosas, de pétalas amarelas, reunidas em racemos. Tem como vetor principal de polinização as abelhas. Suas sementes são lisas e oblongo-achatadas, com tegumento duro e envolta por mesoendocarpo alado. Quando em condições ambientais e de cultivo adequadas, é uma das espécies de mais rápido crescimento nas Regiões Sul e Sudeste. A madeira pode ser usada em obras internas de construção civil e na produção de objetos, sendo indicada tembém para fabricação de polpa e papel de fibra curta (CARVALHO, 1994).

As sementes foram coletadas em Blumenau, SC, em uma área urbana nas proximidades do campus I da Universidade Regional de Blumenau. Após a coleta foi realizada a quebra de dormência através de escarificação mecânica (CARVALHO, 1994). Utilizaram-se 200 sementes de Schizolobium parahyba em experimento montado no dia 4 de outubro de 2006. Foram depositadas, individualmente, em tubetes plásticos de $35 \mathrm{~cm}^{3}$, em substrato composto por casca de arroz carbonizada e areia (1:1) e mantidos em casa de vegetação. 


\subsection{Coleta das amostras para dosagem e tomada de medidas de biomassa e morfometria}

A coleta de amostras representadas por plântulas para dosagem de açúcares solúveis totais, de reserva (amido) e biomassa (massas fresca e seca - MF e MS) foi feita aos 7, 14, 21, 28, 35 e 42 dias após a germinação (DAG), contados a partir do aparecimento de radícula. Foram coletadas 20 amostras por data de coleta. Dessas, 10 amostras foram utilizadas para a mensuração da MF (realizada logo após a coleta), sendo a raiz, hipocótilo, epicótilos (acima dos cotilédones e folhas) e cotilédones segmentados e pesados individualmente, bem como analisados os dados morfométricos (comprimento do hipocótilo e raiz) e mantidos em estufa, durante $24 \mathrm{~h}$ (ou até alcançar massa constante) a $60^{\circ} \mathrm{C}$ e pesadas novamente, obtendo-se, então, a MS. Nas demais 10 amostras foram mensuradas a MF, congeladas em nitrogênio líquido e mantidas sob refrigeração até o término das coletas. Estas foram utilizadas posteriormente para mensuração dos carboidratos.

\subsection{Extração e quantificação dos carboidratos solúveis totais}

Das amostras coletadas e mantidas sob refrigeração, macerou-se $0,5 \mathrm{~g}$ de material oriundo de várias amostras de plântulas germinadas no mesmo tempo de coleta. Em seguida, foram submetidas a fervura em etanol 80\% a $100{ }^{\circ} \mathrm{C}$ em banho-maria, durante 5 min, por três vezes (extração tripla). Os extratos foram centrifugados três vezes a $3.000 \mathrm{rpm}$, por $10 \mathrm{~min}$, e filtrados em microfibra de vidro. Obtiveram-se, então, 22 extrações alcoólicas: quatro extrações para os tempos de coleta de 7, 14, 21 e 28 dias e três para os tempos de coleta de 35 e 42 dias (os cotilédones não estavam mais presentes). $\mathrm{O}$ resíduo sólido foi mantido em refrigeração e, posteriormente, utilizado para quantificação de amido.

A quantificação de açúcares solúveis totais foi feita através de análise colorimétrica, utilizando-se o método do fenol-sulfúrico (DUBOIS et al., 1956), com leitura em espectrofotômetro a $490 \mathrm{~nm}$ de absorbância, sendo a determinação feita para cada uma das partes das plântulas e tempo de coleta, com três repetições para cada extração.

\subsection{Extração e quantificação do amido (carboidratos de reserva)}

Ao resíduo sólido adicionaram-se $1 \mathrm{~mL}$ de água deionizada, esfriada em banho-de-gelo, e 1,3 mL de ácido perclórico 52\%, ambos mantidos por 15 min. Em seguida, foram adicionados mais $2 \mathrm{~mL}$ de água deionizada, e centrifugou-se a $1.500 \mathrm{rpm}$ por $15 \mathrm{~min}$, e filtrou-se o extrato em microfibra de vidro. Para o resíduo sólido foi realizado o mesmo procedimento com metade dos reagentes, depositando a extração juntamente com a primeira fração e ajustando o volume com água deionizada para $10 \mathrm{~mL}$.

A quantificação de amido foi feita da mesma forma que na extração de açúcar.

\subsection{Análise dos dados}

Para cada parâmetro medido - comprimento de raiz e parte aérea, MF e MS das partes das plântulas, quantidade de açúcares (carboidratos) solúveis totais e quantidade de amido (carboidratos de reserva) - foi obtida uma média em cada período de coleta. Nas biomassas calculadas, aplicou-se Análise da Variância (post hoc Tukey-Kramer). Nas médias das leituras dos teores de açúcares foi calculado o desvio-padrão. Para correlacionar os valores de MF com os teores de açúcares solúveis totais e amido, foi feita a regressão entre estes.

\section{RESULTADOS E DISCUSSÃO}

\subsection{Germinação}

As sementes germinaram, considerando-se o aparecimento de radícula, entre o $5^{\circ}$ e $10^{\circ}$ dia após a semeadura, apresentando rápida germinação e desenvolvimento de plântulas, uma característica de espécies pioneiras, cujo percentual foi de $94,5 \%$ de germinação, conforme mostrado na figura 1 . O comprimento das raízes variou entre 12 e $14 \mathrm{~cm}$ e as alturas dos hipocótilos, entre 12 e $17 \mathrm{~cm}$ de comprimento, concordando com Richter et al. (1974), que afirmaram ser $S$. parahyba espécie de rápido crescimento (Figuras 1 e 2).

\section{Germinação}

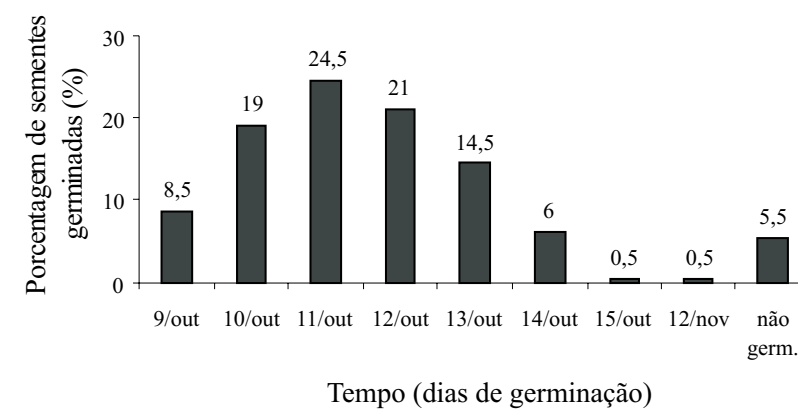

Figura 1 - Percentual de sementes de S. parahyba germinadas ao longo dos dias após a semeadura.

Figure 1 - Percentage of seed germination during the days after sowing.

Revista Árvore, Viçosa-MG, v.34, n.4, p.627-635, 2010

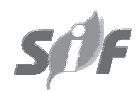




\subsection{Biomassa}

A Tabela 1 mostra que as MFs das raízes não foram significativamente diferentes entre o $35^{\circ}$ e o $42^{\circ} \mathrm{DAG}$, porém diferiram dos demais tempos, com aumento de biomassa principalmente a partir do $28^{\circ}$ DAG. Com relação as MFs dos hipocótilos, estas apresentaram diferenças significativas entre o $14^{\circ}$ e o $21^{\circ}$ DAG e também entre o $14^{\circ}$ e o $35^{\circ}$ DAG, não apresentando diferenças entre os demais períodos, como pode ser observado na tabela 1. Já nos epicótilos as MFs diferiram em quase todos os tempos verificados, mostrando, portanto, que o crescimento dessa estrutura aumentou gradativamente de forma significativa (Tabela 1). Por último, as MF dos cotilédones apresentaram valores significativamente diferentes apenas quando comparados com os valores verificados no $28^{\circ} \mathrm{DAG}$ nos demais tempos de avaliação, porém, mostrando grande redução na biomassa dos cotilédones após o $14^{\circ}$ DAG (Tabela 1).

Com relação à variável MS das raízes de S. parahyba, estas apresentaram diferenças significativas quando comparadas com os resultados obtidos no $7^{\circ}, 14^{\circ} \mathrm{e}$ $42^{\circ}$ DAG, mostrando aumento na biomassa ao longo do desenvolvimento (Tabela 2). Já a MS dos epicótilos aumentou ao longo do desenvolvimento do vegetal, mostrando diferenças de biomassas significativas entre o $7^{\circ}, 21^{\circ}$ e $35^{\circ}$ DAG (Tabela 2). Ainda conforme a Tabela 2, as MSs dos hipocótilos apresentaram poucas diferenças significativas entre si, apenas entre o $7^{\circ}$ e o $42^{\circ} \mathrm{DAG}$. A MS nos cotilédones apresentou maior diferença entre o $7^{\circ}$ e $14^{\circ} \mathrm{DAG}$, reduzindo significativamente no $28^{\circ} \mathrm{DAG}$.

Os cotilédones caíram a partir do $35^{\circ}$ DAG. Apresentaram maiores valores de MS e MF nos primeiros estágios de crescimento da plântula, apresentando biomassas inversamente proporcionais às das outras partes dessa, reduzindo-as à medida que as das outras partes aumentaram. Esses resultados eram esperados, já que os cotilédones são tecidos de reserva, que inicialmente sustentam a plântula. Concordam com os resultados verificados por Corte et al. (2006) na germinação de sementes de Caesalpinia peltophoroides, pertencente à mesma família da espécie estudada neste trabalho, nas quais a biomassa dos

Tabela 1 - Massas frescas (MF) das raízes, hipocótilos, epicótilos e cotilédones (g) de $S$. parahyba no $7^{\circ}, 14^{\circ}, 21^{\circ}, 28^{\circ}$, $35^{\circ}$ e $42^{\circ}$ dia após a germinação.

Table 1 - Fresh biomass of roots, stems, epicotyls and cotyledons (g) of S. parahyba in $7^{\circ}, 14^{\circ}, 21^{\circ}, 28^{\circ}, 35^{\circ}$ and $42^{\circ}$ days after germination.

\begin{tabular}{|c|c|c|c|c|c|c|c|c|}
\hline $\begin{array}{c}\text { Tempo } \\
\text { (dias após germinação) }\end{array}$ & \multicolumn{2}{|c|}{ MF raízes } & \multicolumn{2}{|c|}{ MF hipocótilos } & \multicolumn{2}{|c|}{ MF epicótilos } & \multicolumn{2}{|c|}{ MF cotilédones } \\
\hline 7 & 0,3907 & $\mathrm{~d}$ & 1,2301 & $\mathrm{ab}$ & 0,1530 & $\mathrm{e}$ & 2,0997 & $\mathrm{a}$ \\
\hline 14 & 0,8103 & cd & 1,4038 & $\mathrm{a}$ & 1,3684 & d & 2,1265 & $\mathrm{a}$ \\
\hline 21 & 1,0465 & bc & 1,0993 & $\mathrm{~b}$ & 1,6081 & $\mathrm{~d}$ & 1,8381 & $\mathrm{a}$ \\
\hline 28 & 1,4042 & $\mathrm{~b}$ & 1,1927 & $\mathrm{ab}$ & 2,3990 & C & 0,8759 & $\mathrm{~b}$ \\
\hline 35 & 2,0100 & a & 1,0901 & $\mathrm{~b}$ & 3,1856 & $\mathrm{~b}$ & & \\
\hline 42 & 2,0468 & $\mathrm{a}$ & 1,2056 & $\mathrm{ab}$ & 4,1848 & $\mathrm{a}$ & & \\
\hline
\end{tabular}

Médias seguidas de mesma letra na vertical não diferem entre si, pelo teste de Tukey-Kramer (0,05\%).

Tabela 2 - Massas secas (MS) das raízes, hipocótilos, epicótilos e cotilédones (g) de $S$. parahyba no $7^{\circ}, 14^{\circ}, 21^{\circ}, 28^{\circ}, 35^{\circ}$ e $42^{\circ}$ dia após a germinação.

Table 2 - Dry biomass of roots, stems, epicotyls and cotyledons $(\mathrm{g})$ of S. parahyba in the $7^{\text {th }}, 14^{\text {th }}, 21^{\text {st }}, 28^{\text {th }}, 35^{\text {th }}$, and $42^{\text {nd }}$ after germination.

\begin{tabular}{|c|c|c|c|c|c|c|c|c|}
\hline \multirow{2}{*}{$\begin{array}{c}\text { Tempo } \\
\text { (dias após germinação) } \\
7\end{array}$} & \multicolumn{2}{|c|}{ MF raízes } & \multicolumn{2}{|c|}{ MF hipocótilos } & \multicolumn{2}{|c|}{ MF epicótilos } & \multicolumn{2}{|c|}{ MF cotilédones } \\
\hline & 0,0463 & C & 0,0969 & $\mathrm{C}$ & 0,0211 & $\mathrm{~d}$ & 0,4625 & $\overline{\mathrm{a}}$ \\
\hline 14 & 0,0712 & bc & 0,1229 & bc & 0,1996 & $\mathrm{~cd}$ & 0,2090 & $\mathrm{~b}$ \\
\hline 21 & 0,1251 & abc & 0,1188 & bc & 0,3669 & $\mathrm{c}$ & 0,2000 & $\mathrm{~b}$ \\
\hline 28 & 0,2488 & $\mathrm{ab}$ & 0,1695 & $\mathrm{ab}$ & 0,4295 & bc & 0,0420 & C \\
\hline 35 & 0,2365 & $\mathrm{ab}$ & 0,1607 & abc & 0,6249 & $\mathrm{ab}$ & & \\
\hline 42 & 0,2925 & $\mathrm{a}$ & 0,1918 & $\mathrm{a}$ & 0,8047 & $\mathrm{ab}$ & & \\
\hline
\end{tabular}

Médias seguidas de mesma letra na vertical não diferem entre si, pelo teste de Tukey-Kramer (0,05).

Revista Árvore, Viçosa-MG, v.34, n.4, p.627-635, 2010 
cotilédones nos primeiros dias de avaliação foram as maiores, seguida da redução das biomassas e posterior queda dos cotilédones à medida que as reservas foram exauridas.

Segundo Buckeridge et al. (2004b), espécies pioneiras em geral possuem abundância no número de sementes e geralmente pouca reserva, apresentam dormência, cotilédones fotossintetizantes e necessidade de luz para germinação. A planta no seu desenvolvimento inicial alocou mais recursos para o desenvolvimento dos cotilédones, garantindo as demandas energéticas iniciais das plântulas. S. parahyba representa uma espécie pioneira e possui tais características, entre elas os cotilédones fotossintetizantes. Dessa forma, os cotilédones apresentam similaridade às folhas, com coloração verde, e iniciam rapidamente o processo de fotossíntese desencadeado pelo processo de germinação e desenvolvimento.

Em estudos realizados por Carvalho (2005), com a mesma espécie em questão foi encontrado acúmulo expressivo de açúcares solúveis totais em plântulas submetidas à deficiência hídrica. Esse acúmulo serve de reserva de carbono para a imediata retomada de crescimento, assim que ocorre o balanço hídrico apropriado.

Diante do exposto, os cotilédones de $S$. parahyba realizam processos fotossintéticos, concentrando carbono neles, a fim de que este possua reservas em sua estrutura, para posterior alocação para as demais partes da planta que irão se desenvolver. Então, nos momentos iniciais da germinação, as reservas de carbono permitem a suplementação de energia necessária para o metabolismo celular (BUCKERIDGE et al., 2004b).

As MS e MF apresentaram as maiores médias nos epicótilos a partir do $21^{\circ}$ DAG (Tabelas 1 e 2). Estes resultados concordam novamente com Corte et al. (2006), cujos autores observaram aumento dos epicótilos de C. peltophoroides entre o $5^{\circ}$ e o $35^{\circ}$ dia após a semeadura. Esse aumento de biomassa nos epicótilos coincide com a redução de biomassa nos cotilédones, fato que possivelmente demonstra que nessa fase a planta está alocando substâncias de reserva para os epicótilos, já que a planta precisa desenvolver essa estrutura fotossintetizante para tornar-se autotrófica. Sassaki e Felipe (apud CORTE et al., 2006) também obtiveram resultados semelhantes, nos quais verificaram grande dependência no desenvolvimento de Dalbergia miscolobium em relação às reservas de cotilédones até o $20^{\circ}$ dia após a germinação, quando, então, começou a expansão foliar.

Durante o desenvolvimento de plântulas ocorre a mobilização de reservas para a formação de novas estruturas celulares, porém estas reservas energéticas não são provenientes apenas dos cotilédones, já que no desenvolvimento da plântula os epicótilos se desenvolvem com rapidez, havendo provavelmente contribuição de fotoassimilados provindos das folhas (CORTE et al., 2006). Com o desenvolvimento dos epicótilos, as folhas agora são as maiores responsáveis pela fotossíntese, fato que justifica o aumento de biomassa nessa estrutura, já que o $\mathrm{CO}_{2}$ capturado nesse processo permite que a plântula capte carbono para sua estrutura.

No desenvolvimento de S. parahyba, o hipocótilo cresce até determinado tamanho, e após isso a estrutura que mais aumenta é o epicótilo, formando, juntos, a parte aérea da plântula. Apesar de apresentar algumas diferenças significativas de biomassa nos hipocótilos, esses apresentaram lento incremento no desenvolvimento (Tabela 2). O epicótilo é a estrutura composta pelas folhas, e estas que possibilitam, além da absorção e transporte de água, a absorção de luz e trocas gasosas, principalmente para fixação do $\mathrm{CO}_{2}$. As folhas possuem tecidos fotossintéticos onde estão presentes os estômatos, responsáveis pela maior parte das trocas gasosas realizadas pelas folhas (KERBAUY, 2004). Por ser nas folhas que ocorre mais fotossíntese, o epicótilo desenvolve-se muito mais do que o hipocótilo, fato esse mostrado pelas biomassas pouco alteradas para

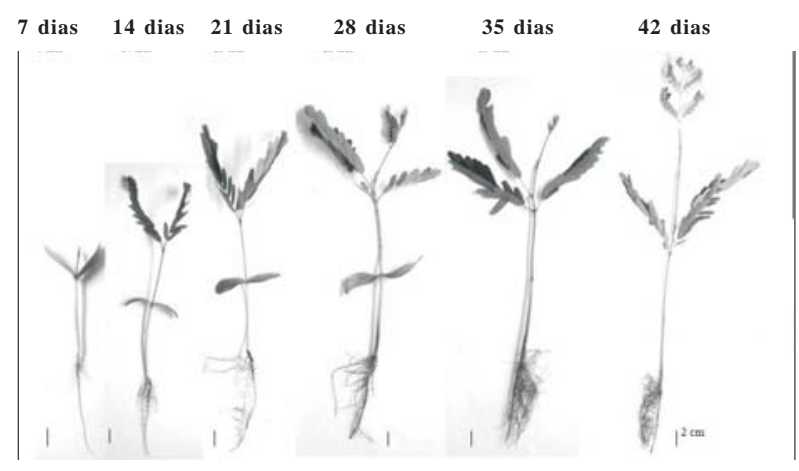

Figura 2 - Plântulas de S. parahyba ao longos dos tempos de coleta $\left(7^{\circ}, 14^{\circ}, 21^{\circ}, 28^{\circ}, 35^{\circ}, 42^{\circ} \mathrm{DAG}\right)$.

Figure 2 - Seedlings of S. parahyba over the days $\left(7^{\text {th }}, 14^{\text {th }}\right.$, $\left.21^{\text {st }}, 28^{\text {th }}, 35^{\text {th }}, 42^{\text {nd }} D A G\right)$.

Revista Árvore, Viçosa-MG, v.34, n.4, p.627-635, 2010 
essa estrutura neste trabalho. Pedrinho et al. (2004) encontraram resultados semelhantes analisando plântulas de soja, que apresentaram maiores MS nas folhas e hipocótilos em comparação com as raízes.

Neste estudo, o crescimento das raízes possivelmente foi reduzido pelo tamanho dos tubetes onde as sementes foram semeadas. Esse é um fator que não permite discutir com segurança sobre o desenvolvimento dessas estruturas. Porém, em condições naturais os sistemas radiculares possivelmente apresentariam pouco desenvolvimento nos estágios iniciais, porque a plântula, de forma geral, investe mais em parte aérea, pois precisa desenvolver essas estruturas para obter rápido crescimento. Nos estágios iniciais de desenvolvimento, as plântulas se desenvolvem tendo como fonte de carbono, além das reservas cotiledonares, a fotossíntese (BUCKERIDGE et al., 2004a). A plântula precisa investir em estruturas que assimilem carbono, ou seja, que façam fotossíntese para garantir a sua condição autotrófica.

\subsection{Teores de Açúcares Solúveis Totais e Açúcares de Reserva (amido)}

Na Figura, 3 mostram-se as concentrações de açúcares solúveis totais em partes de plântulas de $S$. parahyba. As raízes e hipocótilos apresentaram teores de açúcares solúveis totais diferindo do $7^{\circ}$ ao $21^{\circ}$ DAG. A partir do $28^{\circ} \mathrm{DAG}$ ocorreu aumento gradual dos teores de açúcares, especialmente nos hipocótilos e epicótilos (Figura 3).

No $14^{\circ}, 21^{\circ}$ e $28^{\circ}$ DAG, as maiores quantidades de açúcar se fizeram presentes nos epicótilos (Figura 3). Isso provavelmente se deveu ao fato de que, a partir dessa fase de desenvolvimento, alocação dos recursos não é mais proveniente apenas dos cotilédones, mas também das demais partes da plântula que realizam fotossíntese. Por essa razão, a plântula investe nos epicótilos, de onde recebem os fotoassimilados ricos em energia, tornando-a autotrófica. Isso se justifica, pois folhas imaturas retêm grande parte de carbono para síntese de seus constituintes celulares, podendo inclusive importar carbono de outras partes da planta (KERBAUY, 2004). As partes das plântulas que estão em crescimento possuem altos teores de açúcares solúveis totais, pois a planta precisa desses compostos de carbono para desenvolver suas estruturas e desenvolver as plântulas. Por S. parahyba ser espécie

Revista Árvore, Viçosa-MG, v.34, n.4, p.627-635, 2010

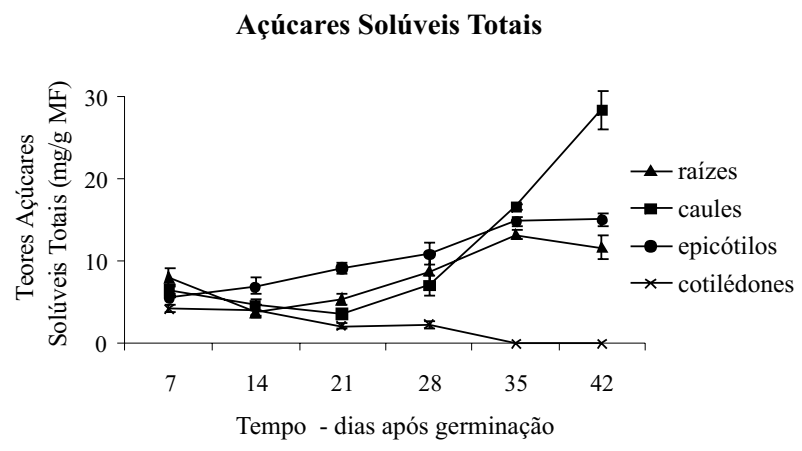

Figura 3 - Teores de açúcares solúveis totais em mg/gMF, no $7^{\circ}, 14^{\circ}, 21^{\circ}, 28^{\circ}, 35^{\circ}$ e $42^{\circ}$ dias após a germinação, em raízes, hipocótilos, epicótilos e cotilédones de S. parahyba.

Figure 3-Total soluble sugar levels in $\mathrm{mg} / \mathrm{g}$ of fresh biomass during the $7^{\text {th }}, 14^{\text {th }}, 21^{\text {st }}, 28^{\text {th }}, 35^{\text {th }}$, and $42^{\text {nd }} D A G$ in roots, stems, epicotyls and cotyledons of $\boldsymbol{S}$. parahyba.

pioneira, suas plâtulas precisam de rápido desenvolvimento, para tanto alocam açúcares solúveis em maiores concentrações durante essa fase.

O aumento dos teores dos açúcares solúveis totais nos epicótilos coincidiu com a redução da quantidade de açúcares dos cotilédones, conforme mostrado na Figura 3, corroborando o fato de que nos primeiro dias de crescimento a fotossíntese pode ser realizada pelos cotilédones e, em seguida, pelos epicótilos. Esses teores concordam com os valores de biomassa.

Na Figura 4, mostram-se as concentrações de amido nas partes de plântulas de $S$. Parahyba. Houve grande mobilização do amido cotiledonar no $7^{\circ}$ e $14^{\circ}$ DAG.

Os cotilédones apresentaram altas concentrações de amido quando comparados com as das demais partes das plantas, representando, então, os valores elevados de biomassa encontrados nessas estruturas (Figura 4 e Tabela 1 ).

Com mesma tendência verificada nos teores de açúcares solúveis totais, o aumento nos teores de amido nos hipocótilos e epicótilos coincidiu com a redução da quantidade de amido nos cotilédones (Figura 4). Isso auxilia novamente na compreensão de que, inicialmente, as reservas de amido nos cotilédones são necessárias para fornecer recursos para a plântula que irá se desenvolver, seguido de maior alocação de amido para epicótilos ao longo do desenvolvimento da parte aérea em geral. 


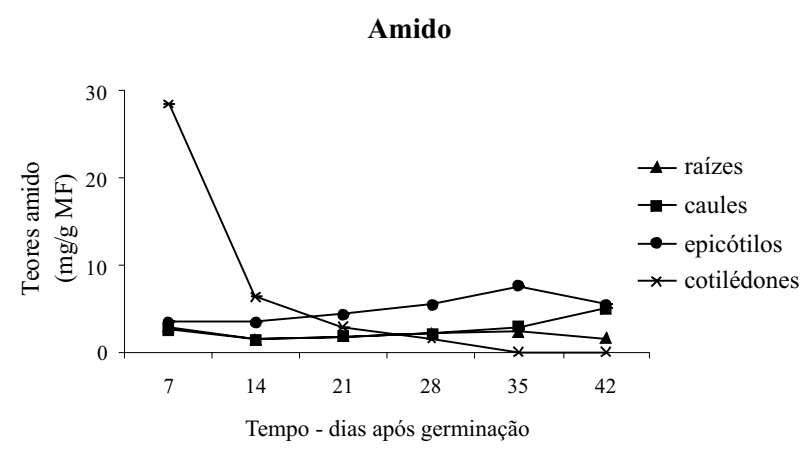

Figura 4 - Teores de amido em mg/gMF aos 7,14, 21, 28, 35 e 42 dias após a germinação, em raízes, hipocótilos, epicótilos e cotilédones de $S$. parahyba.

Figure 4 -Starch levels in $\mathrm{mg} / \mathrm{gFB}$ during the $7^{\text {th }}, 14^{\text {th }}$, $21^{\text {st }}, 28^{\text {th }}, 35^{\text {th }}$, and $42^{\text {nd }}$ DAG in roots, stems, epicotyls and cotyledons of S. parahyba.

A assimilação de carbono é o resultado do balanço de trocas de $\mathrm{CO}_{2}$ que as plantas realizam. Essa assimilação não depende somente da intensidade das trocas gasosas, como também da proporção entre a massa dos órgãos fotossinteticamente ativos e tecidos não fotossinteticamente ativos e da proporção entre os períodos favoráveis e desfavoráveis para a assimilação. A proporção de massa verde fotossinteticamente ativa, em relação à massa total, depende da forma de crescimento do vegetal, das modificações durante o desenvolvimento e da influência dos fatores ambientais (LARCHER, 2000). Os açúcares solúveis totais observados nos hipocótilos e epicótilos da espécie estudada não são oriundos necessariamente somente da hidrólise do amido, mas também da fotossíntese que essas estruturas aéreas em desenvolvimento já estão realizando.

Comparando as Figuras 3 e 4, é possível observar que ocorreram maiores concentrações de amido nos cotilédones, enquanto nas demais partes das plântulas os açúcares solúveis totais estiveram em maiores concentrações. O amido representa as biomassas dos órgãos de reserva, e os açúcares oriundos de sua quebra são alocados para as demais partes da planta como carboidrato na forma de açúcares solúveis totais. Segundo Buckeridge et al. (2004b), o amido é sintetizado nas folhas durante o dia, a partir da fixação fotossintética de carbono, e mobilizado para os outros tecidos, seja de crescimento ou de reserva. O amido é hidrolisado nos tecidos que o acumulam. Portanto, a redução da quantidade de amido é uma consequência da atividade da amilase que o degrada, sendo acompanhado por aumento da quantidade de açúcares solúveis (FILHO, 2001). Esses resultados concordam com aqueles verificados por Corte et al. (2006), que encontraram pequenas concentrações de amido nas sementes de Caesalpinia peltophoroides, e também com Machado et al. (1989), que obtiveram menores teores de amido quando comparados com os teores de açúcares solúveis totais em folhas de Theobroma cacao. Trabalhos com Veratrum album relataram maiores biomassas e teores de açúcares e amido nas raízes e nos hipocótilos (KLEIJN et al., 2005).

O aumento nos teores de açúcares solúveis totais mostrou correlação com o aumento de MF nos epicótilos $\left(\mathrm{R}^{2}=0,95 ; \mathrm{P}<0,05\right)$ e raízes $\left(\mathrm{R}^{2}=0,94 ; \mathrm{P}<0,05\right)$. Em contrapartida, a redução nos teores de açúcares acompanhou a redução das MF nos cotilédones até queda ou abscisão dos cotilédones $\left(\mathrm{R}^{2}=0,70\right.$; $\left.\mathrm{P}<0,05\right)$.

As correlações entre as MFs e o amido foram positivas apenas entre as MFs dos epicótilos $\left(\mathrm{R}^{2}=0,92 ; \mathrm{P}<0,05\right)$ e das raízes $\left(\mathrm{R}^{2}=0,90 ; \mathrm{P}<0,05\right)$.

Através das correlações entre as biomassas e os teores de açúcares solúveis totais e de reserva, foi possível observar com clareza que o aumento nos teores de açúcares solúveis totais nos epicótilos e raízes foi diretamente proporcional ao aumento de biomassa destes.Assim, quando os cotilédones diminuíram sua biomassa, também houve redução das quantidades de açúcares solúveis totais, e, da mesma forma, as biomassas dos epicótilos foram maiores, quando as quantidades de açúcares solúveis totais neles aumentaram. Isso mostra que o incremento de biomassa é proveniente dos açúcares distribuídos nos epicótilos provindos dos cotilédones. Esses dados concordam com aqueles verificados por Corte et al. (2006), que afirmaram que a redução da MS dos cotilédones de C. peltophoroides está diretamente associada à redução nos compostos de reserva nele estocados e associada também ao aumento da MS das plântulas.

Em estudos realizados por Durda et al. (2006), sementes de $S$. parahyba foram separadas em pequenas, médias e grandes, a fim de analisar os teores de açúcares solúveis e amido, não encontrando, no entanto, diferenças nos teores nas três classes de tamanho. Encontraram maiores teores de amido nos cotilédones e de açúcares solúveis no eixo hipocótilo-radícula. Esses dados mostram que, antes da germinação das sementes, os cotilédones 
já possuem altos teores de amido como reserva e que os outros compostos de carbono já começam a ser alocados para o eixo hipocótilo-radícula. Perin et al. (2004) observaram que as reservas das sementes de maior tamanho são utilizadas no desenvolvimento inicial das plântulas, que é mais vigoroso do que em plântulas oriundas de sementes pequenas, as quais podem compensar o menor crescimento inicial em estágios posteriores de crescimento. Portanto, possivelmente existe tendência de disponibilidade de açúcares solúveis totais em zonas de crescimento. Em S. parahyba, tal característica tem importância pelo fato de ser espécie pioneira. Precisa de rápido crescimento, e para tanto aloca açúcares solúveis para as partes da planta, como foi encontrado neste estudo.

\section{CONCLUSÃO}

As relações de biomassa e teores de açúcares solúveis totais e amido encontrados neste trabalho ressaltam a mobilização dos compostos de reserva (amido) e a alocação desses recursos dos cotilédones para as outras partes da planta, à medida que a diminuição da biomassa e açúcares dos cotilédones reflete no aumento da produção de biomassa de epicótilos, hipocótilos e raízes da plântula.

O aumento da MF é diretamente proporcional ao incremento de açúcares solúveis e amido nas estruturas analisadas. Os açúcares solúveis e o amido são fontes de energia para a plântula. O primeiro está presente em maior quantidade nas raízes, hipocótilos e epicótilos da espécie estudada do que o amido, apresentando, portanto, açúcares prontamente assimiláveis, importantes para o estabelecimento das plântulas. Porém, o amido é o que representa os maiores teores nos cotilédones nos estágios iniciais, justificando ser esse um tecido de reserva. O amido quando quebrado fornece vazão para a disponibilidade dessa fonte de energia para as demais partes da plântula.

Os açúcares solúveis encontrados nos epicótilos e hipocótilos, além de serem alocados dos cotilédones através da hidrólise do amido, são oriundos da fotossíntese que essas partes da plântula realizam.

Os altos teores de açúcares solúveis alocados para epicótilos são necessários para suprir a demanda de rápido crescimento de S. parahyba como espécie pioneira.

Revista Árvore, Viçosa-MG, v.34, n.4, p.627-635, 2010

\section{REFERÊNCIAS}

BUCKERIDGE, M. S. et al. Acúmulo de reservas. In:FERREIRA, A. G.; BORGHETTI, F. Germinação: do básico ao aplicado. Porto Alegre: Artmed, 2004a. 324 p.

BUCKERIDGE, M. S. et al. Mobilização de reservas. In:FERREIRA, A. G.; BORGHETTI, F. Germinação: do básico ao aplicado. Porto Alegre:Artmed, 2004b. 324 p.

BUCKERIDGE, M. S.; DITRICH, S. M. C. Mobilisation of the rafinose family oligossaccharides and galactomannan in germinating seeds of Sesbania marginata Benth. (Leguminosae-Faboideae). Plant Science, v.117, n.1, p.33-43, 1996.

CARVALHO, P. E. R. Espécies Arbóreas Brasileiras: recomendações silviculturais, potencialidades e uso da madeira. Brasília: Embrapa-SPI, 1994. 640p.

CARVALHO, C. J. R. Respostas de plantas de Schizolobium amazonicum [S. parahyba var. amazonicum] e Schizolobium parahyba [Schizolobium parahybum] à deficiência hídrica. Revista Árvore, v.29, n.6, p.907-914, 2005.

CORTE, V. B. et al. A Mobilização de reservas durante a germinação das sementes e crescimento das plântulas de Caesalpinia peltophoroides Benth. (LeguminosaeCaesalpinoideae). Revista Árvore, v.30, n.6, p.941-949, 2006.

DUBOIS, M. et al. Colorimetric method for determination of sugars and related substances. Anal. Chem., v.28, n.3, p.350-356, 1956.

DURDA, F.; PESCADOR, R.; UHLMANN, A. Dosagem de carboidratos nas sementes de Schizolobium parahyba e Talauma ovata de acordo com o tamanho seminal. Revista Brasileira de Biociências, v. 5, supl. 2, p. 465-467, 2007.

.CHAVES FILHO, J. T. C.; STACCIARINISERAPHIN, E. Alteração no potencial osmótico e teor de carboidratos solúveis em plantas jovens de lobeira (Solanum lycocarpum St-Hil.) em resposta ao estresse hídrico. Revista Brasileira de Botanica., v.24, n.2, p.199-204, 2001. 
GIBSON, S. T. Sugar and phytohormone response pathways: navigating a signaling network. Journal of Experimental Botany., v.55, n.395, p.253-263, 2003.

GRUBB, P. J. The maintenance of species-richness in plant communities: the importance of the regeneration niche. Biological Reviews, v.52, n.4, p.107-145, 1977.

KERBAUY, G. B. Fisiologia vegetal. Rio de Janeiro: Guanabara Koogan, 2004. 472p.

KLEIJN, D.; TREIER, U. A.; MÜLLER-SCHÄRER, H. The importance of nitrogen and carbohydrate storage for plant growth of the alpine herb Veratrum album. The New Phytologist, v.166, n.2, p.565-575, 2005.

LARCHER, W. Ecofisiologia vegetal. São Carlos: RiMa Artes e Textos, 2000. 319p.

MACHADO, R. C. R.; MÜLLER, M. W.; BARRETO, E. W. S. Variações diurnas no teor de amido e de açúcares solúveis em folhas de cacau (Theobroma cacao L.). Revista Brasileira de Fisiologia Vegetal, v.1, n.2, p.163-167, 1989.

PEDRINHO, A. F. F.; BIANCO, S.; PITELLI, R. A. Acúmulo de massa seca e macronutrientes por plantas de Glycine max e Richardia brasiliensis. Planta Daninha, v.22, n.1, p.53-61, 2004.
PERIN, A.; ARAÚJO, A. P.; TEIXEIRA, M. G. Efeito do tamanho da semente na acumulação de biomassa e nutrientes e na produção do feijoeiro. Pesquisa Agropecuária Brasileira, v.37, n.12, p.1711-1718, 2004.

RICHTER, H. H.; TOMASELLI, I.; MORESCHI, J. C. Estudo tecnológico do Guapuruvu (Schizolobium parahybum). Revista Floresta, v.5, n.1, p.26-30, 1974.

RICKLEFS, R. E. A economia da natureza. 5. ed. Rio de Janeiro: Guanabara Koogan, 2003. 503p.

SUDA, C. N. K.; GIORGINI, J. F. Seed reserve composition and mobilization during germination and initial seedling development of Euphorbia heterophylla. Revista Brasileira de Fisiologia Vegetal, v.12, n.3, p.226-245, 2000.

TREVISAN, R. et al. Teores de açúcares em plantas de pereira (Pyrus serotina REHDER) NAK., CV. NIJISSEIKI submetidas à desfolha total e poda de gema no final do ciclo de crescimento. Reviata

Brasileira de Agrociência, v.9, n.2, p.117-119, 2003. 